\title{
Serotonin Expression in Lichen Planus Lesions and Its Relationship with Depression/Anxiety
}

\author{
Gökçe Işıl Kurmuş, Müzeyyen Gönül ${ }^{1}$, Filiz Canpolat ${ }^{1}$, Demet Y1lmazer ${ }^{2}$, Eylem Şahin Cankurtaran ${ }^{3}$ \\ Department of Dermatology, Medical Park Ankara Hospital, Departments of ${ }^{1}$ Dermatology, ${ }^{2}$ Pathology, and ${ }^{3}$ Psychiatry, Dışkap Yıldırım \\ Beyazit Training and Research Hospital, Ankara, Turkey
}

\begin{abstract}
Background: Psychological factors such as stress, depression, and anxiety have been documented to contribute to the development of lesions in lichen planus (LP). Objective: To evaluate the relationship between serotonin expression in LP lesions and depression/anxiety. Methods: Forty patients (22 females, 18 males) with LP and 20 healthy control subjects were included in this study. The severity of LP was assessed with the palmar method (using the measurement of affected body surface area [BSA]). The depression and anxiety scores were measured with Beck's depression inventory (BDI) and Beck's anxiety inventory (BAI). The expression of serotonin was determined via immunohistochemistry in LP lesions and in the control group skin using a monoclonal antibody to serotonin. Results: The skin biopsies of the LP patients had significantly higher levels of serotonin than those of the control subjects $(p<0.001)$. In the LP patients, and there was a positive correlation between serotonin expression and LP severity $(p=0.022)$. Based on the results from the BDI and BAI, there was a significant relationship between the severity of depression/anxiety and intensity of serotonin expression ( $p$ $<0.001)$. Conclusion: Data from this study suggest that serotonin may have a possible role in the pathogenesis of LP. Further, the relationship between serotonin expression in
\end{abstract}

Received May 29, 2018, Revised October 2, 2018, Accepted for publication October 6, 2018

Corresponding author: Gökçe Işıl Kurmuş, Department of Dermatology, Medical Park Ankara Hospital, Kent Koop, 1868. Street, No:15, Batıkent/ Yenimahalle, Ankara 06680, Turkey. Tel: 903126668000, Fax: 902122273477, E-mail: isilkurmus@gmail.com ORCID: https://orcid.org/0000-0002-4087-404X

This is an Open Access article distributed under the terms of the Creative Commons Attribution Non-Commercial License (http://creativecommons. org/licenses/by-nc/4.0) which permits unrestricted non-commercial use, distribution, and reproduction in any medium, provided the original work is properly cited.

Copyright $(c)$ The Korean Dermatological Association and The Korean Society for Investigative Dermatology acute cutaneous lesions and the depression/anxiety scores indicates that serotonin may be a mediator for the association of LP and depression/anxiety simultaneously. There is a need for more specific studies showing the expression of serotonin in the lichen planus to demonstrate the cause or effect. (Ann Dermatol 31(2) $146 \sim 153,2019$ )

\section{-Keywords-}

Anxiety, Depression, Lichen planus, Serotonin

\section{INTRODUCTION}

Lichen planus (LP) is a chronic inflammatory dermatosis of unknown etiology affecting the skin, mucosa, nails, and hair. T-lymphocyte-mediated delayed-type cellular immune response plays a major role in the pathogenesis of this disease $^{1-5}$. Psychological factors such as stress, depression, and anxiety have been documented to contribute to the development of lesions in LP. Along with genetic predisposition, depression and anxiety are well-known triggering factors at the onset and during the course of LP, as they alter immune function ${ }^{6-8}$. The most widely accepted view in depression etiology is that depression reduces the efficiency of noradrenaline and serotonin ${ }^{9,10}$. It has been suggested that proinflammatory cytokines such as interleukin $1 \beta$ (IL-1 $\beta)$, IL-6, and tumor necrosis factor $\alpha$ (TNF- $\alpha$ ) increase during major depression, and they may also cause major depression ${ }^{11}$. Further, it has been reported that depression can lead to immune hyperactivation, resulting in an increase in Th1 cytokines $^{12,13}$.

Some recent studies with immunohistochemical analysis have shown that serotonin expression was increased in the epithelial and adnexal structures in the lesions of chronic inflammatory skin disease, such as eczema and 
psoriasis, compared to normal $\operatorname{skin}^{14,15}$. To our knowledge, serotonin expression in LP has never been studied. Therefore, we aimed to determine the contribution of serotonin in the pathobiology of LP by examining serotonin expression in the LP lesions and by evaluating the relationship between serotonin expression, the severity of $L P$, and Beck's depression inventory (BDI) and Beck's anxiety inventory (BAI) scores in patients with LP.

\section{MATERIALS AND METHODS}

\section{Study groups}

This study was conducted at Ankara Dışkapı Yıldırım Beyazıt Training and Research Hospital, Dermatology Clinic, between November 2013 and May 2014. Forty patients clinically and histopathologically diagnosed with LP and 20 healthy control subjects were enrolled. All of the patients were over 18 years of age. The patients were analyzed for dermatological symptoms. Approval for this project as well as written permission was obtained by the ethics committee of the hospital and from patients and control subjects, respectively (Ethic committee no. 11/15-11/11/ 2013).

Patients were selected for this study using inclusion criteria as follows: active lesions, no other major physical/psychiatric influential history that may affect the results of the BDI/BAI, no history for at least three months of any regular systemic therapy, no history for at least 3 months of systemic LP therapy, and no history for at least 1 month before the study of any LP topical treatment. Patients with only mucosal, scalp or nail complications or with erosive or severe oral LP were also excluded. The main reason for exclusion of these patients were: chronicity, severity, difficulty in the treatment of those types of LP. As the features mentioned above naturally raises the depression/anxiety scores of the study groups, they were not included in this study. The age and sex-matched healthy controls had no history of skin or psychiatric disorders.

Patients that met inclusion criteria for this project were informed about the study. Nail, mucosal, and scalp involvement were recorded, as was the severity of the LP. The severity of the LP was assessed with the palmar method (using the measurement of affected body surface area [BSA]). Traditionally, the palmar surface area of hand has been evaluated to be one percent of total body surface area. Patients were classified into 3 groups based on BSA involvement $(0 \% \sim 25 \%, 26 \% \sim 50 \%$, and $51 \% \sim 75 \%)$. Other data were recorded, including age, gender, duration of disease, medical and family histories, clinical signs, age of disease onset, treatment and duration, depression/anxi- ety presence, psychiatric history, and previous psychiatrist visits. All of the participants completed the BDI/BAI. Both the patient and control subjects were evaluated by the department of psychiatry, and scored with the following point system: $0 \sim 13$ with the BDI indicated no depression, 14 19 mild depression, 24 28 moderate depression, and $>29$ severe depression. According to the BAI point system, 0 9 indicated no anxiety, 10 16 mild anxiety, $17 \sim 29$ moderate anxiety, and $>30$ severe anxiety.

\section{Immunohistochemical staining}

Serotonin expression was examined immunohistochemically in LP skin lesions and in control subjects. Four millimeter punch biopsies were formalin fixed (10\%) and stained with hematoxylin and eosin. For staining, $3 \mathrm{mi}-$ cron sections were subjected to antigen-retrieval using a microwave oven $\left(20\right.$ minutes at $\left.100^{\circ} \mathrm{C}\right)$. Sections were placed in 3\% hydrogen peroxide at room temperature for 15 minutes to quench any endogenous peroxidases, and then washed in phosphate-buffered saline (PBS) for 5 minutes. A serotonin mouse monoclonal antibody $(5 \mathrm{HT}-\mathrm{H} 209$, Catalog Number: GTX31099; GeneTex Inc., Irvine, CA, USA) was diluted 1:20 and incubated with the sections for 1 hour. Tissue sections were washed three times with PBS for 5 minutes, followed by peroxidase-conjugated streptavidin complex incubation at room temperature for $15 \mathrm{~min}$ utes. The sections were incubated for 20 minutes in the chromogenic substrate 3,3' diaminobenzidine. As a positive control, formalin-fixed and paraffin embedded normal appendix vermiformis samples were used. The staining results for serotonin expression in the epidermis, mononuclear inflammatory cells, sebaceous glands, eccrine glands, and capillary endothelial cells were evaluated. Positive stained cells were scored by percentage and intensity in the epidermis, and only for intensity in the sebaceous glands, eccrine glands, and capillary endothelial cells. For staining intensity, the following four-point scale was used: Grade 0, no staining $(-)$; Grade 1, mild staining $(+)$; Grade 2, moderate staining $(++)$; and Grade 3, strong staining $(+++)$.

\section{Statistical analysis}

Statistical evaluation was performed by SPSS version 11.5 (SPSS Inc., Chicago, IL, USA). Differences in serotonin expression between the patients and controls were determined with the chi-square test, while the KruskalWallis test was used for the affected BSA, the BDI/BAI scores, and other individual variables. Spearman correlation coefficients were estimated to determine correlations between variables. A p-value of less than 0.05 was considered statistically significant. 


\section{RESULTS}

A total of 40 LP patients were enrolled in the study with 22 female (55\%) and 18 male subjects (45\%). For the control group, there were 7 females $(35 \%)$ and 13 males $(65 \%)$. The mean ages of LP patients and controls were $48.6 \pm 15.6$ and $41.0 \pm 12.7$ years, respectively. No significant differences within groups based on gender and age were determined.

The LP lesions were localized on the extremities of most patients, and papular lesions were the most common morphological pattern. Of the patients, 35\% also had extracutaneous LP lesions. Duration of the disease was $\leq 6$ months in $80 \%$ of the patients. BSA was $<25 \%$ in $72.5 \%$ of the patients. The detailed clinical characteristics of the LP patients are presented in Table 1.

Table 1. Demographics and clinical features of LP patients

\begin{tabular}{|c|c|c|}
\hline Variable & $\begin{array}{c}\text { Mean } \pm \text { standard } \\
\text { deviation }\end{array}$ & Number (\%) \\
\hline Age & $48.6 \pm 15.6$ & \\
\hline \multicolumn{3}{|l|}{ Gender } \\
\hline Male & & $18(45.0)$ \\
\hline Female & & $22(55.0)$ \\
\hline \multicolumn{3}{|l|}{ Lesion location } \\
\hline Lower extremity & & $2(5.0)$ \\
\hline Trunk & & $2(5.0)$ \\
\hline Trunk + lower extremity & & $4(10.0)$ \\
\hline Trunk + upper extremity & & $8(20.0)$ \\
\hline Trunk + upper + lower extremity & & $4(10.0)$ \\
\hline Palmar & & $1(2.5)$ \\
\hline Upper extremity & & $9(22.5)$ \\
\hline Upper + lower extremity & & $10(25.0)$ \\
\hline \multicolumn{3}{|l|}{ Lesion morphology } \\
\hline Annular & & $1(2.5)$ \\
\hline Bullous & & $1(2.5)$ \\
\hline Guttate & & $3(7.5)$ \\
\hline Hypertrophic & & $1(2.5)$ \\
\hline Papular & & $34(85.0)$ \\
\hline Other involvement & & $14(35.0)$ \\
\hline Oral & & $5(12.5)$ \\
\hline Genital & & $3(7.5)$ \\
\hline Nail & & $9(22.5)$ \\
\hline \multicolumn{3}{|l|}{ Disease duration (mo) } \\
\hline $0 \sim 6$ & & $32(80.0)$ \\
\hline $7 \sim 12$ & & $6(15.0)$ \\
\hline$>12$ & & $2(5.0)$ \\
\hline \multicolumn{3}{|l|}{ BSA $(\%)$} \\
\hline $0 \sim 25$ & & $29(72.5)$ \\
\hline $26 \sim 50$ & & $7(17.5)$ \\
\hline $51 \sim 75$ & & $4(10.0)$ \\
\hline Total & & $40(100.0)$ \\
\hline
\end{tabular}

LP: lichen planus, BSA: body surface area.
The mean BDI and BAI scores of the LP patient group were $17.6 \pm 9.4$ and $10.5 \pm 8.5$, respectively, while they were $9.7 \pm 7.3$ and $5.9 \pm 4.4$ in the control group (Table 2); these differences were significant (BDI, $p<0.001$; $\mathrm{BAI}$, $p=0.024)$. When all were assessed for the prevalence of depression on BDI, 22 out of 40 patients (55\%) and 6 out of 20 controls $(30 \%)$ had depression. In addition, the LP group had more depression in numbers than did the control group, but no significance was determined ( $p=0.067)$. Further, the presence of anxiety was higher in LP patients than the control group $(p=0.005)$. According to BAI scores, 21 out of 40 patients $(52.5 \%)$ and 3 out of 20 controls $(15 \%)$ had anxiety respectively.

According to the BDI scores, 6 of the LP patients had severe depression, 13 had moderate depression, 3 had mild depression, and 18 did not have depression. Anxiety was detected in $21 \mathrm{LP}$ patients and in 3 controls (Fig. 1). Based on the BDI and BAI scores, LP patient depression and anxiety levels were higher compared to controls (BDI, $p=0.034 ; \mathrm{BAI}, p=0.008$ ).

Of the biopsy specimens in the LP group, 31 (77.5\%) were positive for serotonin. Three of these $(7.5 \%)$ had a grade 3 staining intensity, $13(32.5 \%)$ were grade 2 , and $15(37.5 \%)$ were grade 1 . Only three $(15 \%)$ specimens in the control group stained positive for serotonin, and all of these were grade 1 . The intensity of serotonin staining was significantly higher in the LP tissue compared to controls $(p<0.001$, Table 3). Moderate and strong serotonin expression (grades 2 and 3) was detected in the inflammatory cells, eccrine glands, and capillary endothelial cells in the LP group; the control group had no moderate or severe staining (Table 4, Fig. 2, 3).

Data showing the relationship between the severity of LP and the intensity of serotonin expression is presented in Table 5. There was a positive association with serotonin expression in the lesional skin of LP and affected body surface area $(p=0.022)$. Patients with $51 \% \sim 75 \%$ BSA had higher serotonin expression in the tissue than those who had $0 \% \sim 25 \%$ BSA $(p<0.001)$. However, no substantial difference in serotonin expression was determined in pa-

Table 2. BDI and BAI values

\begin{tabular}{lccc}
\hline BDI and BAI values & LP $(n=40)$ & Controls $(n=20)$ & $p$-value \\
\hline BDI mean & $17.6 \pm 9.4$ & $9.7 \pm 7.3$ & $<0.001^{*}$ \\
Depression presence & $22(55.0)$ & $6(30.0)$ & 0.067 \\
BAI mean & $10.5 \pm 8.5$ & $5.9 \pm 4.4$ & 0.024 \\
Anxiety presence & $21(52.5)$ & $3(15.0)$ & 0.005 \\
\hline
\end{tabular}

Values are presented as mean \pm standard deviation or number (\%). BDI: Beck's depression inventory, BAI: Beck's anxiety inventory, LP: lichen planus. *Statistically significant. 
A

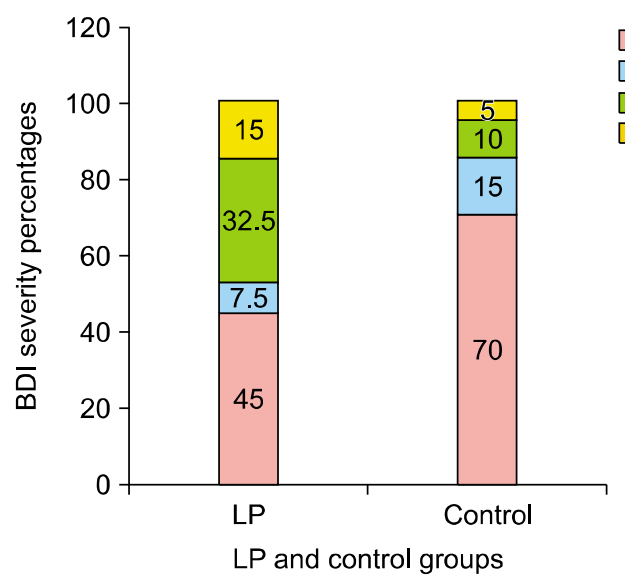

B

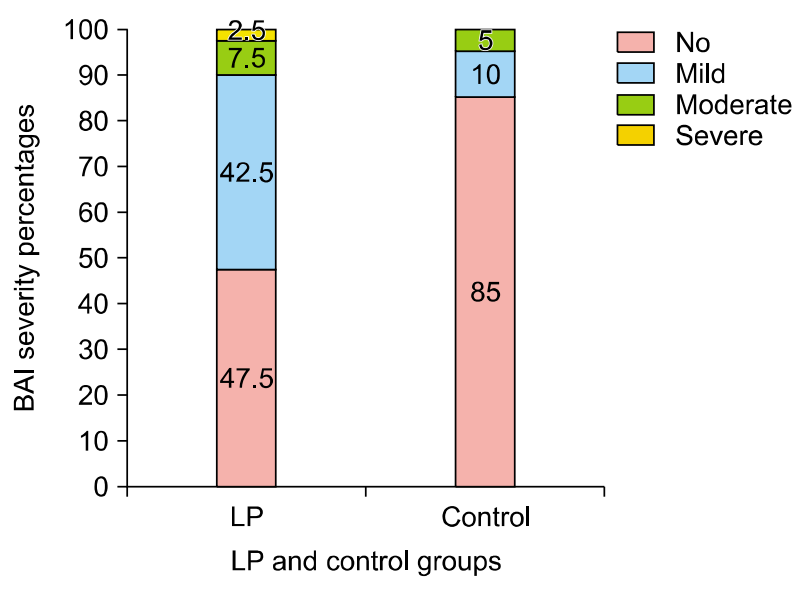

Fig. 1. (A) BDI values, (B) BAI values. BDI: Beck's depression inventory, BAI: Beck's anxiety inventory, LP: lichen planus.

Table 3. The intensity of serotonin staining in the tissue of patient and control groups

\begin{tabular}{|c|c|c|c|}
\hline & LP $(n=40)$ & Control $(n=20)$ & $p$-value \\
\hline Serotonin staining intensit & & & $<0.001^{*}$ \\
\hline Grade 0 & $9(22.5)$ & $17(85.0)$ & \\
\hline Grade 1 & $15(37.5)$ & $3(15.0)$ & \\
\hline Grade 2 & $13(32.5)$ & - & \\
\hline Grade 3 & $3(7.5)$ & - & \\
\hline
\end{tabular}

Values are presented as number (\%). LP: lichen planus. Grade 0 : no staining $(-)$, Grade 1 : mild staining $(+)$, Grade 2: moderate staining $(++)$, Grade 3 : strong staining $(+++)$. * Statistically significant.

tients with $0 \% \sim 25 \%$ BSA and $26 \% \sim 50 \%$ BSA $(p=0.060)$, or between patients with $26 \% \sim 50 \%$ BSA and $51 \% \sim 75 \%$ BSA $(p=0.099)$.

Data showing the relationship between serotonin expression intensity and the presence of depression and anxiety (based on BDI/BAl scores) is summarized in Table 6. Serotonin expression was positive in all subjects with LP and depression. The intensity of serotonin expression was higher in LP patients with depression and anxiety than those without $(p<0.001)$. Furthermore, a significant correlation between the severity of depression/anxiety and serotonin staining intensity in the LP patient group was determined $(p<0.001)$.

\section{DISCUSSION}

In our study, we investigated if there is a relationship between serotonin expression and depression/anxiety severity in LP patients. We found that the mean $\mathrm{BDI}$ and $\mathrm{BAI}$ scores of LP patients were higher than the control group. The intensity of serotonin staining was significantly higher
Table 4. The serotonin expression areas in the skin of patient and control groups

\begin{tabular}{lcc}
\hline \multicolumn{1}{c}{ Layers of the skin } & LP & Control \\
\hline Stratum corneum & - & - \\
Stratum granulosum & - & - \\
Basal cell layer & - & - \\
Inflammatory cell & + & - \\
Eccrine gland & + & + \\
Sebaseous gland & - & - \\
Collagen fibers & - & - \\
Capillary endothelial cell & + & - \\
\hline
\end{tabular}

LP: lichen planus, - : not available, + : available.

in LP tissue compared to control. There was a positive association with serotonin expression and severity of LP. Furthermore, a significant correlation between the severity of depression/anxiety and serotonin staining intensity in LP patients was determined.

While the etiology of LP has not been fully elucidated, various infectious, genetic, immunological, and psychogenic factors are thought to be possible causes ${ }^{5,6,8}$. Recent studies have focused on psychological factors (e.g., stress, depression and anxiety) in the development of lesions in $\mathrm{LP}$, which is a psychodermatologic disease. Most of these reports have studied oral lichen planus, and the results are controversial $^{16-25}$.

Some recent immunohistochemical studies have shown that compared to normal skin, the expression of serotonin and its receptors in epithelial and adnexal structures was increased in the lesions of those with chronic inflammatory skin disease, including psoriasis, chronic eczema, allergic contact dermatitis, and atopic dermatitis ${ }^{14,15,26-30}$. To our knowledge, our current study is the first to investigate serotonin expression in the lesions of LP. Results in- 

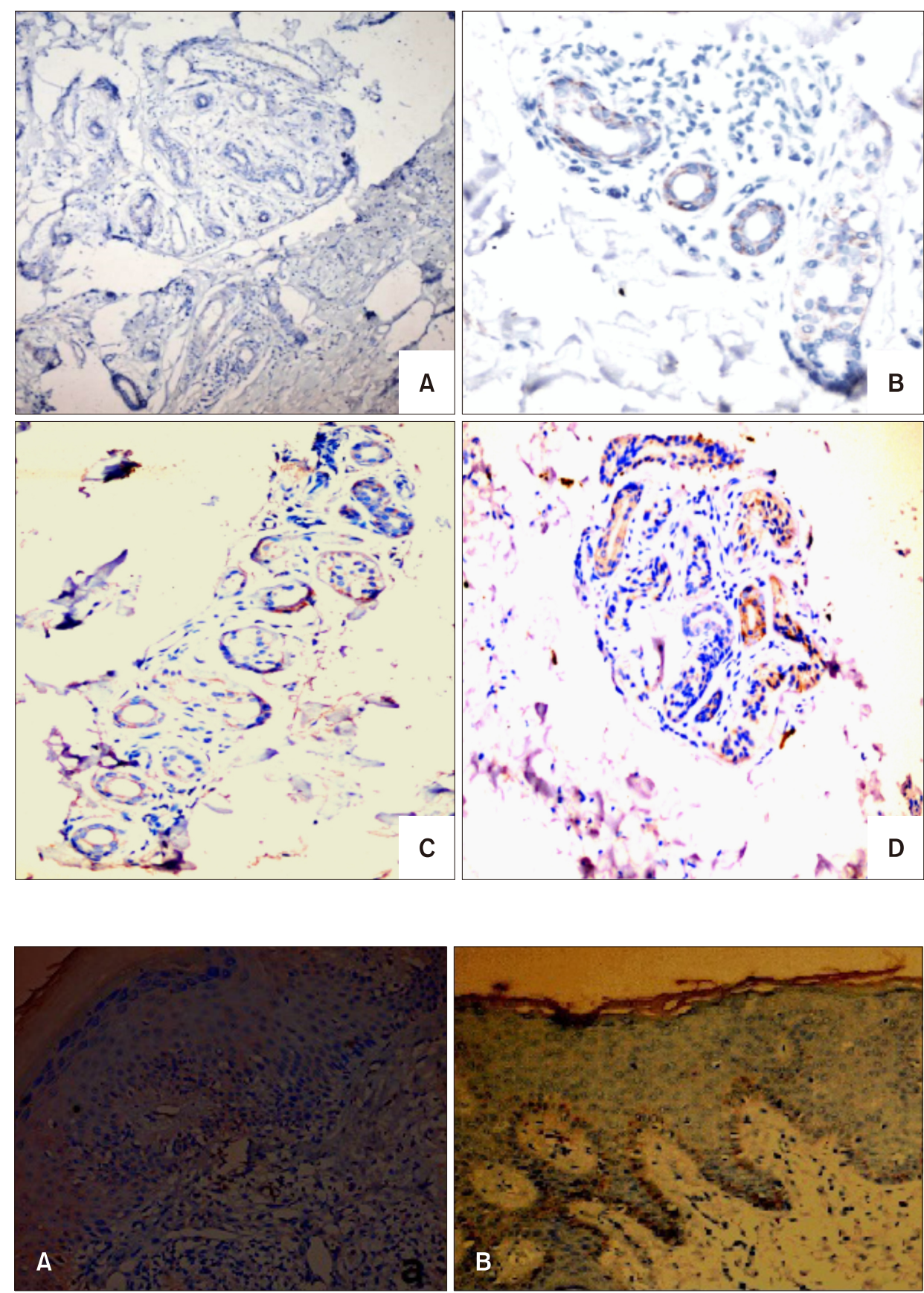

Fig. 2. Serotonin expression in the eccrine glands of lichen planus lesions (serotonin mouse monoclonal antibody, $10 \times 20$ ). (A) Grade 0, no staining ( - ); (B) Grade 1, mild staining (+); (C) Grade 2, moderate staining $(++)$; (D) Grade 3, strong staining $(+++)$.

Fig. 3. Immunohistochemical staining of lichen planus lesions for serotonin. (A) Grade 2, moderate staining $(++)$. (B) Grade 3, strong staining $(+++)$. dicated that serotonin expression in the LP lesions was significantly increased over that of normal skin in the control group. When all biopsy specimens were assessed for the serotonin staining, 31 out of $40(77.5 \%)$ were serotonin positive in the LP patients group. Only 3 out of 20 (15\%) specimens in the control group stained positive for serotonin. Based on this result, we put forth that serotonin may be important in the development of LP lesions.

Results of the present study revealed serotonin expression in inflammatory cells, eccrine glands, and capillary endothelial cells, but not in epithelial structures. Only 3 of the specimens in the control group had positive serotonin staining in the eccrine glands, while 21 in the LP group were positive. While serotonin expression was positive in the inflammatory cells and capillary endothelial cells in the LP patient group, it was negative in these cells of the control group. These data indicate that serotonin may play a role in LP pathogenesis via the eccrine glands and inflammatory cells. In addition, serotonin can contribute to inflammation by altering capillary permeability. Similar to the results of our current study, Huang et al. observed stronger positive expression of serotonin in the adnexial 
Table 5. Relationship between BSA and serotonin expression in patients

\begin{tabular}{lccccc}
\hline \multirow{2}{*}{$\begin{array}{c}\text { Serotonin } \\
\text { expression }\end{array}$} & $\begin{array}{c}0 \sim 25 \\
(\mathrm{n}=29)\end{array}$ & $\begin{array}{c}26 \sim 50 \\
(\mathrm{n}=7)\end{array}$ & $\begin{array}{c}51 \sim 75 \\
(\mathrm{n}=4)\end{array}$ & $p$-value \\
\cline { 2 - 5 } & & & & & $0.022^{*}$ \\
$\begin{array}{l}\text { Serotonin staining } \\
\text { intensity }\end{array}$ & $8(27.6)$ & $1(14.3)$ & - & \\
- & $13(44.8)$ & $2(28.6)$ & - & \\
+ & $7(24.1)$ & $3(42.9)$ & $3(75.0)$ & \\
++ & $1(3.4)$ & $1(14.3)$ & $1(25.0)$ & \\
+++ & &
\end{tabular}

Values are presented as number (\%). BSA: body surface area. - : no staining, + : mild staining, ++ : moderate staining, +++ : strong staining. ${ }^{*}$ Statistically significant.

structures (e.g., sweat and sebaceous glands and hair follicles) of psoriasis lesions compared to normal skin ${ }^{14}$. From these observations, the authors hypothesized that because adnexial structures all derive from epithelial cells, the expression of serotonin in these cells is similar to that in epithelial cells. We suggest that serotonin is important in the pathogenesis of LP by affecting both the inflammatory and capillary endothelial cells. In addition, sweat glands may also be involved in this process, although through an unknown mechanism.

Studies investigating the relationship between serotonin and inflammation have reported that serotonin increases $T$ lymphocyte proliferation and the production of IL- 6 and TNF- $\alpha$ by different receptors ${ }^{31-33}$. Further, dermal injection of serotonin can initiate a delayed-type hypersensitivity immune response by causing CD4 + T lymphocyte activation and collection ${ }^{27}$. Serotonin can be synthesized by monocytes and lymphocytes, and therefore, cytokine production from these cells causes it to have autocrine functions; for example, IL-1 $\beta$ increases serotonin re-uptake into the cells and also increases the levels of mRNA and proteins in the serotonin reuptake system ${ }^{32}$. We believe that our data support these previously published data, and hypothesize that increased serotonin expression in inflammatory cells may lead to the production of proinflammatory cytokines. Further, this increased serotonin expression may be important in the pathogenesis of LP, which is a disease impacted by T-cells. Experimental studies have shown that 5-HT2 antagonists inhibit delayedtype hypersensitivity, and that 5-HT1 antagonists inhibit the synthesis of Th1 cytokines $^{32}$. It has also been shown that 5 -HT2 antagonists inhibit the synthesis of TNF- $\alpha$ and interferon- $\gamma^{34}$. We believe that serotonin antagonists may be an effective treatment for LP lesions, and that the development of topical serotonin antagonists will significantly
Table 6. The relationship between serotonin expression and the presence of depression/anxiety according to BDI/BAI in patient and control groups

\begin{tabular}{|c|c|c|c|c|}
\hline \multirow{2}{*}{$\begin{array}{l}\text { Serotonin } \\
\text { expression }\end{array}$} & \multicolumn{2}{|c|}{ No } & \multicolumn{2}{|c|}{ Presence } \\
\hline & LP & Control & LP & Control \\
\hline \multicolumn{5}{|c|}{ BDI depression } \\
\hline \multicolumn{5}{|c|}{ Serotonin staining intensity } \\
\hline- & $9(50.0)$ & $12(85.8)$ & - & $5(83.3)$ \\
\hline+ & $9(50.0)$ & $2(14.2)$ & $6(27.3)$ & $1(16.7)$ \\
\hline++ & - & - & $13(59.1)$ & - \\
\hline+++ & - & - & $3(13.6)$ & - \\
\hline \multicolumn{5}{|l|}{ BAI anxiety } \\
\hline \multicolumn{5}{|c|}{ Serotonin staining intensity } \\
\hline- & $9(47.4)$ & $14(82.4)$ & - & $3(100)$ \\
\hline+ & $8(42.1)$ & $3(17.6)$ & 7 (33.3) & - \\
\hline++ & $1(5.3)$ & - & $12(57.1)$ & - \\
\hline+++ & $1(5.3)$ & - & $2(9.5)$ & - \\
\hline
\end{tabular}

Values are presented as number (\%). BDI: Beck's depression inventory, BAI: Beck's anxiety inventory, LP: lichen planus, -: not available. - : no staining, + : mild staining, ++ : moderate staining, +++ : strong staining.

contribute to the treatment of LP. Abovementioned local inflammatory mechanisms may induce pruritus in cutaneous lesions of LP. However, the underlying mechanisms of itch in LP remain still unknown. Proinflammatory cytokines such as IL-31, TNF- $\alpha$, proteases from apoptotic cells, some members of toll-like receptors family, opioid system, and serotonin are possible mediators implicated to transmit or modulate itch ${ }^{35}$. Itch is the most unpleasant and bothersome symptom of LP for majority of patients in the study. The relationship between pruritus and serotonin expression can be investigated by using an itch scala.

In our current study, serotonin expression in lesional skin was significantly more prominent in patients with depression and anxiety than those without. Further, the amount of serotonin positivity was significantly increased with increasing depression/anxiety scores from the BDI/BAI. To our knowledge, the relationship between serotonin expression and depression/anxiety has not yet been investigated in any dermatological disease. Our study is the first to examine the relationship between serotonin expression in LP lesions and depression/anxiety scores. However, we could not fully analyze the relationship between serotonin expression and depression/anxiety scores in the control group because of the sample size. We hope that this study will inspire others to conduct larger studies on this topic. The activation of the stress-induced hypothalamus pituitary axis causes increased glucocorticoid levels, and therefore, higher levels of serotonin in the circulation. Serotonin contributes to delayed-type hypersensitivity by increasing 
both $\mathrm{T}$ lymphocyte proliferation and the production of proinflammatory cytokines. Increased proinflammatory cytokines in the circulation leads to decreased levels of serotonin; this is because cytokines increase the degradation and reuptake of serotonin in the presynaptic space in the central nervous system ${ }^{11,32-34}$. The increased tissue expression of serotonin in patients with depression/anxiety may be due to the movement of serotonin from the circulation to the skin by an unknown mechanism, or by the augmented synthesis of serotonin in the skin, which may be caused by increased cytokines in depression. In our current study, there was a significant correlation between depression/anxiety scores and the expression of serotonin in the tissue, which supports this hypothesis.

Several studies have shown that psychological factors including anxiety/depression/stress play a role in LP. Chronic inflammatory diseases such as psoriasis and atopic dermatitis are examples of diseases with disrupted stabilization of the neuro-immuno-cutaneous system (NICS). It has been suggested that inflammation may cause disturbances in the NICS, which may further induce inflammation and increase serotonin expression; this may trigger T-cell mediated inflammation, which plays a role in the pathogenesis of LP. The same triggering factor may cause imbalances in the NICS and lead to depression, or on the other hand, depression may cause inflammation in the skin through mediators such as serotonin. The prevalence of depression and anxiety in oral LP patients is well known. The data from this study have revealed a relationship between serotonin expression in acute cutaneous lesions and the depression/anxiety scores of LP patients, therefore suggesting a possible role of serotonin in the pathogenesis of LP, which is a psychodermatologic disorder. Moreover, serotonin may play a mediator role in the pathogenesis of both LP lesions and depression simultaneously. We suggest that modulation of serotonin levels and treatment of depression/anxiety may lead to a novel therapeutic pathway for reducing inflammation in LP.

Our current study has some limitations. First, this is a cross-sectional study, and therefore, the associations can be interpreted either as causes or consequences. Second, this study has a small sample size, and therefore, these results need to be substantiated in a bigger sample population. Further, the relationship between serotonin and itching should be determined with an itch scale. Overall, future investigations are necessary to support the results of this study and to explain the relationship between serotonin expression and LP.

\section{ACKNOWLEDGMENT}

This study was supported by the Dışkapı Yıldırım Beyazıt Training and Research Hospital Scientific Research Projects Commission. The authors have nothing to disclose.

\section{CONFLICTS OF INTEREST}

The authors have nothing to disclose.

\section{ORCID}

Gökçe Işı Kurmuş, https://orcid.org/0000-0002-4087-404X Müzeyyen Gönül, https://orcid.org/0000-0003-1914-2175

Filiz Canpolat, https://orcid.org/0000-0002-5722-6479

Demet Yılmazer, https://orcid.org/0000-0002-1637-0415

Eylem Şahin Cankurtaran, https://orcid.org/0000-0002-7337-6653

\section{REFERENCES}

1. Boyd AS, Neldner KH. Lichen planus. J Am Acad Dermatol 1991;25:593-619.

2. Lehman JS, Tollefson MM, Gibson LE. Lichen planus. Int J Dermatol 2009;48:682-694.

3. Marshman G. Lichen planus. Australas J Dermatol 1998;39: 1-11.

4. Shiohara T, Kano Y. Lichen planus and lichenoid dermatoses. In: Bolognia J, Jorizzo JL, Schaffer JV, editors. Dermatology. 3rd ed. Philadelphia, PA: Elsevier Saunders, 2012.

5. Daoud MS, Pittelkow MR. Lichen planus. In: Freedberg IM, Eisen AZ, Wolf K, Austen KF, Goldsmith LA, Katz SI, et al, editors. Fitzpatrick's dermatology in general medicine. 7th ed. New York: McGraw-Hill, 1999:561-577.

6. Gorouhi F, Davari P, Fazel N. Cutaneous and mucosal lichen planus: a comprehensive review of clinical subtypes, risk factors, diagnosis, and prognosis. ScientificWorldjournal 2014;2014:742826.

7. James WD, Berger TG, Elston DM. Lichen planus and related condition. In: James WD, Elston DM, Berger TG, Andrews GC, editors. Andrews' diseases of the skin: clinical dermatology. 11th ed. Philadelphia, PA: Elsevier Saunders, 2011.

8. Roopashree MR, Gondhalekar RV, Shashikanth MC, George J, Thippeswamy SH, Shukla A. Pathogenesis of oral lichen planus--a review. J Oral Pathol Med 2010;39:729-734.

9. Öztürk MO, Uluşahin NA. Ruh Sağlığı ve Bozuklukları. Ankara: Hekimler Yayın Birliği, 1994.

10. Tamam L, Zeren T. Depresyonda serotonerjik düzenekler. Klinik Psikiyatri Dergisi 2002;5:11-18.

11. Müller N. Immunology of major depression. Neuroimmunomodulation 2014;21:123-130.

12. Leonard BE. The HPA and immune axes in stress: the involvement of the serotonergic system. Eur Psychiatry 2005;20 Suppl 3:S302-S306. 
13. Rödström PO, Jontell $M$, Hakeberg $M$, Berggren $U$, Lindstedt G. Erosive oral lichen planus and salivary cortisol. J Oral Pathol Med 2001;30:257-263.

14. Huang J, Li G, Xiang J, Yin D, Chi R. Immunohistochemical study of serotonin in lesions of psoriasis. Int J Dermatol 2004;43:408-411.

15. Huang J, Li G, Xiang J, Yin D, Chi R. Immunohistochemical study of serotonin in lesions of chronic eczema. Int J Dermatol 2004;43:723-726.

16. Akay A, Pekcanlar A, Bozdag KE, Altintas L, Karaman A. Assessment of depression in subjects with psoriasis vulgaris and lichen planus. J Eur Acad Dermatol Venereol 2002;16: 347-352.

17. Allen CM, Beck FM, Rossie KM, Kaul TJ. Relation of stress and anxiety to oral lichen planus. Oral Surg Oral Med Oral Pathol 1986;61:44-46.

18. Bergdahl J, Ostman PO, Anneroth G, Perris H, Skoglund A. Psychologic aspects of patients with oral lichenoid reactions. Acta Odontol Scand 1995; 53:236-241.

19. Chaudhary S. Psychosocial stressors in oral lichen planus. Aust Dent J 2004;49:192-195.

20. Ivanovski K, Nakova M, Warburton G, Pesevska S, Filipovska A, Nares S, et al. Psychological profile in oral lichen planus. J Clin Periodontol 2005;32:1034-1040.

21. Koray M, Dülger O, Ak G, Horasanli S, Uçok A, Tanyeri H, et al. The evaluation of anxiety and salivary cortisol levels in patients with oral lichen planus. Oral Dis 2003;9: 298-301.

22. Lundqvist EN, Wahlin YB, Bergdahl M, Bergdahl J. Psychological health in patients with genital and oral erosive lichen planus. J Eur Acad Dermatol Venereol 2006;20:661-666.

23. Rojo-Moreno JL, Bagán JV, Rojo-Moreno J, Donat JS, Milián MA, Jiménez Y. Psychologic factors and oral lichen planus. A psychometric evaluation of 100 cases. Oral Surg Oral Med Oral Pathol Oral Radiol Endod 1998;86:687-691.

24. Soto Araya M, Rojas Alcayaga G, Esguep A. Association between psychological disorders and the presence of Oral lichen planus, Burning mouth syndrome and Recurrent aphthous stomatitis. Med Oral 2004;9:1-7.

25. Vallejo MJ, Huerta G, Cerero R, Seoane JM. Anxiety and depression as risk factors for oral lichen planus. Dermatology 2001;203:303-307.

26. El-Nour H, Lundeberg L, Abdel-Magid N, Lonne-Rahm SB, Azmitia EC, Nordlind K. Serotonergic mechanisms in human allergic contact dermatitis. Acta Derm Venereol 2007;87:390-396.

27. Lonne-Rahm SB, Rickberg $\mathrm{H}$, El-Nour $\mathrm{H}$, Mårin $\mathrm{P}$, Azmitia EC, Nordlind K. Neuroimmune mechanisms in patients with atopic dermatitis during chronic stress. J Eur Acad Dermatol Venereol 2008;22:11-18.

28. Nordlind K, Thorslund K, Lonne-Rahm S, Mohabbati S, Berki $\mathrm{T}$, Morales $\mathrm{M}$, et al. Expression of serotonergic receptors in psoriatic skin. Arch Dermatol Res 2006;298: 99-106.

29. Thorslund K, Amatya B, Dufva AE, Nordlind K. The expression of serotonin transporter protein correlates with the severity of psoriasis and chronic stress. Arch Dermatol Res 2013;305:99-104.

30. Thorslund K, El-Nour H, Nordlind K. The serotonin transporter protein is expressed in psoriasis, where it may play a role in regulating apoptosis. Arch Dermatol Res 2009;301:449-457.

31. Kushnir-Sukhov NM, Brown JM, Wu Y, Kirshenbaum A, Metcalfe DD. Human mast cells are capable of serotonin synthesis and release. J Allergy Clin Immunol 2007;119: 498-499.

32. Mössner R, Lesch KP. Role of serotonin in the immune system and in neuroimmune interactions. Brain Behav Immun 1998;12:249-271.

33. Sperner-Unterweger B, Kohl C, Fuchs D. Immune changes and neurotransmitters: possible interactions in depression? Prog Neuropsychopharmacol Biol Psychiatry 2014;48: 268-276.

34. Ahern GP. 5-HT and the immune system. Curr Opin Pharmacol 2011;11:29-33.

35. Welz-Kubiak K, Reich A. Mediators of pruritus in lichen planus. Autoimmune Dis 2013;2013:941431. 